\title{
Pit dewatering optimisation of a 3D FEFLOW unstructured groundwater model at geologically complex Antamina mine site in Peru
}

RM Dufour DHI Peru SAC and UNINE, Peru

C Aguirre Antamina, Peru

M Sanchez Antamina, Peru

A Maqueda Université de Neuchâtel, Switzerland

JM Zwinger DHI WASY GmbH, Germany

A Renz DHI WASY GmbH, Germany

J Cho Independent Consultant, Canada

D Evans FloSolutions, Peru

\begin{abstract}
Hydrogeological models are a simplification of reality and cannot incorporate all complexities which exist in nature. Modellers must decide on the level of detail necessary for a given problem based on the objective of the modelling exercise. Geology and structures play an important role in groundwater flow at mine sites in the Peruvian Andes (FloSolutions 2015). At the Antamina mine, flow is strongly controlled by faults, fracturing associated with bedding, folding and karstic features within limestone formations (Beal 2014). In addition, since Antamina is a skarn-type deposit, the intrusion has induced a complex geological system that governs the flow behaviour around the metamorphosised contact between the intrusion and the limestone host rock. This complexity makes the process of open pit dewatering and the evaluation of pore pressures for pit slope stability and geotechnical analysis challenging. Three-dimensional (3D) unstructured meshing in FEFLOW allows for an increased level of detail in the open pit and a better representation of the geological complexity and structures, at the same time allowing conservation of the 3D flow process at a regional scale with fewer mesh nodes in the numerical model and therefore, shorter simulation time. In addition to highlighting the new FEFLOW capabilities for unstructured meshes for pit dewatering; this paper presents innovative optimisation processes to minimise OPEX and CAPEX of the dewatering operation and a data fusion solution to significantly increase the accuracy of pore pressure simulation outputs for pit slope analysis.
\end{abstract}

Keywords: FEFLOW $7 x$, mine dewatering, pore pressure, optimisation of OPEX, cloud computing, complex geological settings, Andes

\section{Summary}

The first part of this paper describes the evolution of the Antamina, open pit model, originally a 3D layer-based model made in 2012 (MWH 2012). This model-named the 2012 layered model-was developed prior to the release of the unstructured grid capabilities of FEFLOW 7.1 (DHI 2015) and was rebuilt by the same team of modellers using an unstructured mesh in 2016. For the new model, named the 2016 unstructured model, a new geological model constructed in Leapfrog (BISA 2015) was inserted into the FEFLOW model mesh. 54 faults were explicitly incorporated into the new model in addition to 13 geological units and a hydrogeological zonation with depth leading to a total of over 800 adjustable parameters (SRK 2011). Additionally, the geometry of all the pit stages from the 2016 to 2036 mine plans are represented with high detail within the FEFLOW mesh by adjusting the mesh node locations to match the mine planes 
(Figure 1). The 2016 unstructured model was calibrated in steady and transient states using head data from more than 165 piezometers. Using Amazon's cloud computing was mandatory to shorten the calibration process from weeks to days, using PEST (Doherty 2016). Another critical component of the 2016 unstructured model was the insertion of 36 mine plan designs within the unstructured mesh itself. Having such a level of detail allowed a direct 3D pore pressure stability analysis using Flac 3D (Itasca 2012). This is an exercise that is typically done externally from the 3D FEFLOW model using 2D vertical models such as SEEP/W (Geoslope 2012) due to the need for a high mesh density in the pit area that was not previously possible to achieve in regional 3D layer-based model. The 2D vertical-section groundwater flow model approach comes with the limitation of ignoring 3D flow processes towards the open pit and could potentially bias the pore pressure solution from 3D process. Geotechnical models themselves don't have the limitation of being restricted to $2 \mathrm{D}$ model pore pressure, so it's a computational burden related to the 3D groundwater model.

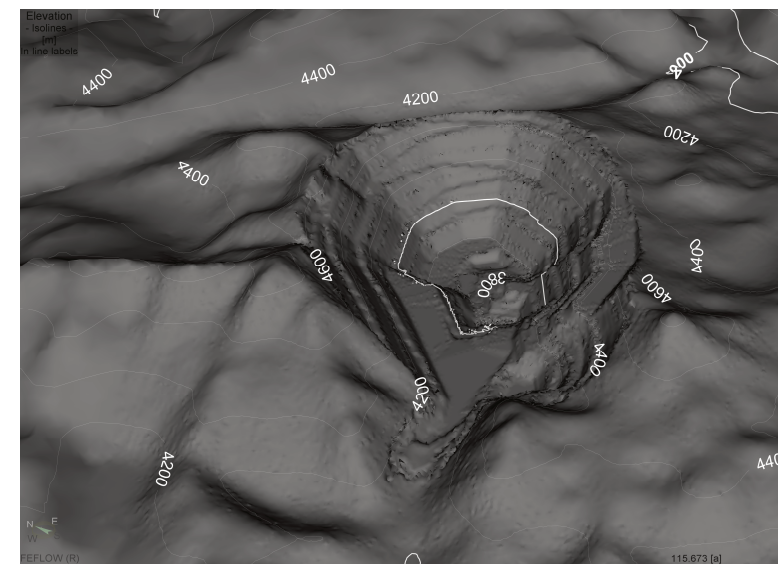

(a)

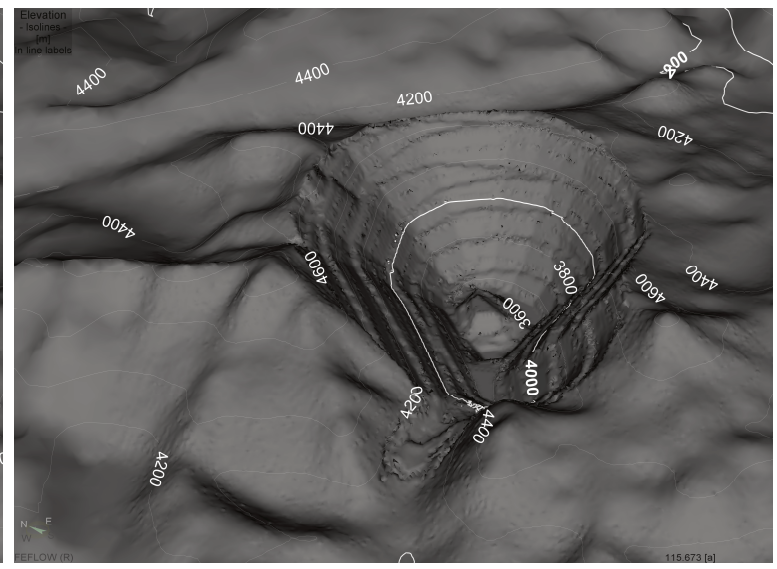

(b)

Figure 1 3D view of the 2016 unstructured model illustrating the high level of detail product of the unstructured mesh for the 2025 (a) pit stage and (b) final pit stage where even the ramps of the mine are represented

The second part of this paper will describe the optimisation process. The goal was to perform a numerical and automatic optimisation of dewatering/depressurisation well locations with regards to a CAPEX-and-OPEX objective function. FEFLOW was automated using an external MATLAB routine to test all the possible pumping well locations in a defined area for each of the 20 years of the mine plan. The possible well locations correspond to nodes in the FEFLOW mesh, $100 \mathrm{~m}$ below the pit bottom at each year of the mining plan. The effect of each well location was then analysed automatically through the optimisation process to find the most efficient combination of well locations for dewatering, while at the same time, reducing the cost function. A dynamic algorithm was used because it can handle discrete and mixed problems (selecting the number of wells to implement and deciding which ones need to be activated and at which rates). The approach consists of generating a rather large set of possible solutions (a population) and computing the objective function for all those solutions. Then all unacceptable configurations (those with high objective function values) are rejected. New solutions are generated by making random perturbations within the accepted solutions and by adding some new combinations around those. The process is repeated multiple times until the objective function no longer decreases. During the process, the predominant computational demand is caused by the computation of the drainage response in FEFLOW. To minimise this computational burden, accelerate the process, and explore all the possible combinations in-depth, the calculation of the hydraulic heads was linearised where possible.

The final part of the paper describes how highly accurate pore pressure distributions for the pit slope stability model have been derived by merging the model results with actual observed pressure transducer data. The data fusion method has been applied to create the best linear unbiased estimate of the pressure field before passing the data to the pit slope stability model. The difference made by this bias correction method 
is shown by comparing the raw 2016 unstructured model output with the results from this augmentation process for the 2015 period of the model.

\section{$2 \quad$ Model construction and unstructured mesh}

\subsection{Geological characterisation}

Geology is a key factor for the behavior of the groundwater system at the Antamina mine site (FloSolutions 2015) and (WMC 2009), especially the near-pit structures which tend to create hydrogeological compartments within the flow system. The regional geology comprises several different limestone units that have been subject to faulting, folding, and, in some cases, karst development. In the pit area, there are various types of alterations and intrusive units. Antamina is a skarn-type deposit formed at the metamorphosised contact between the intrusion and the limestone host rock. Geological complexityespecially in and around the pit zone-poses challenges to the development of a groundwater flow model that is detailed enough to provide pit pore pressures for a geotechnical stability assessment. Because individual geological units were observed to have distinct influences on the groundwater flow regime, importing an existing 3D Leapfrog model with a smooth interface to FEFLOW was required. The geological model (BISA 2015) was provided by Antamina and is shown in Figure 2. Figure 3 shows its representation in the 2016 unstructured model. To be precise, the model in Figure 3 represents a fusion of two geological models; the regional Antamina property model (geological formations and regional faults) merged with the more detailed open pit wide model (lithology).

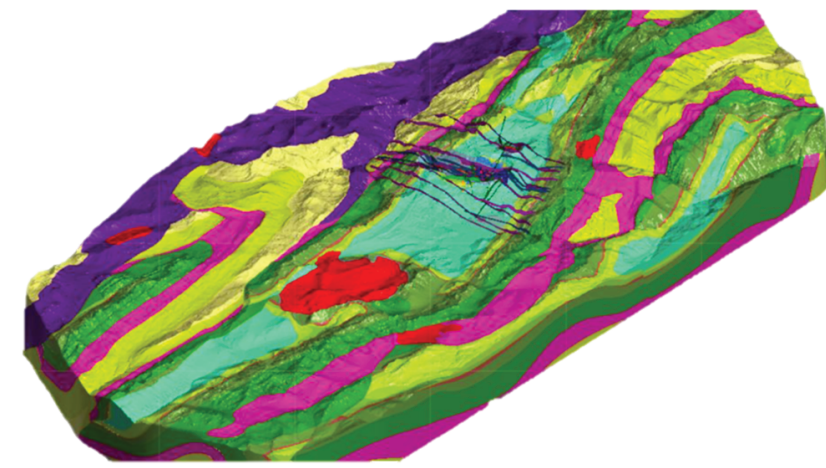

(a)

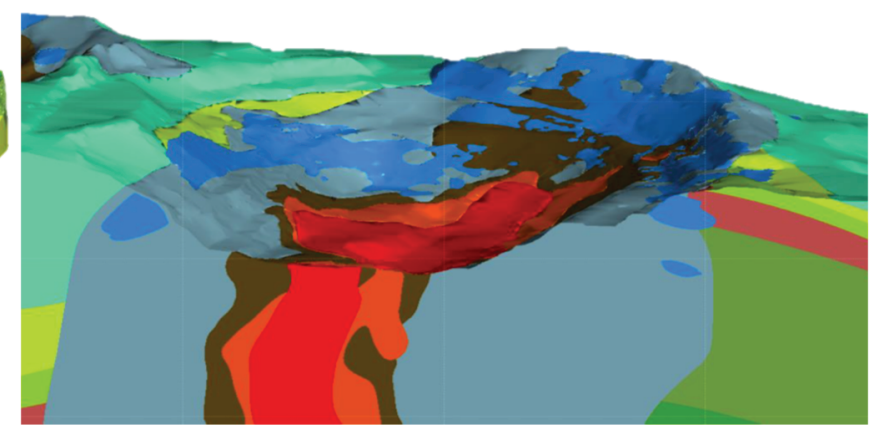

(b)

Figure 2 (a) View of the 3D Leapfrog model; (b) Zoom in the pit area of the Leapfrog model

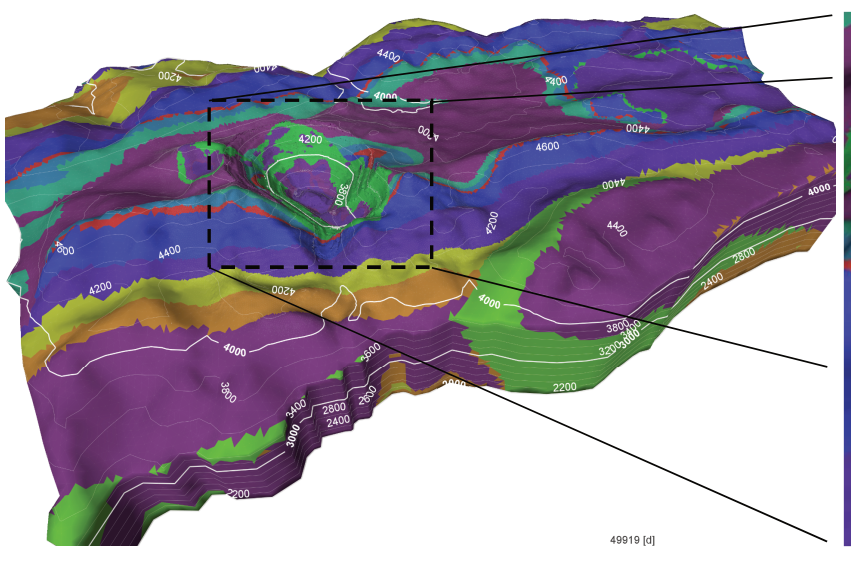

(a)

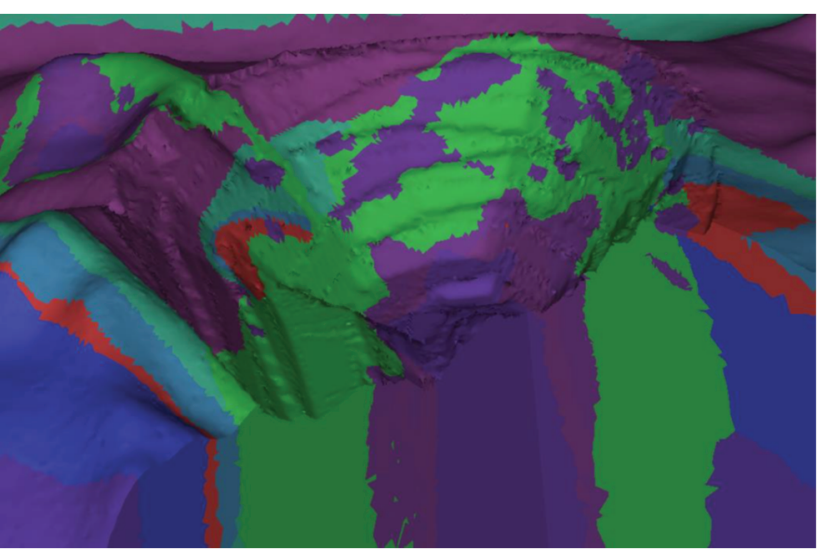

(b)

Figure 3 View of the 2016 unstructured model including the geological information imported from the Leapfrog model and zoom of the zone of interest - open pit. (a) General view of the Leapfrog model imported within the 2016 unstructured model; (b) Zoom in the Pit are showing the detailed representation of the geology 


\subsection{Definition of the faults}

The few mapped regional faults from the Leapfrog geological model were not explicitly defined within the 2016 unstructured model since they were distant from the pit area. However, 54 local faults (Figures 4(a) and (b)) from the Leapfrog model were incorporated into the 2016 unstructured model within the open pit area. This represents one of the major advances from the 2012 layered MWH model built in FEFLOW version 6.2 (DHI 2013), which was only capable of modelling vertical faults or simplifying an inclined fault into large discrete steps due to the computational burden related to refinement required in the open pit area. Faults in Antamina are important hydrogeological features since they can both impede groundwater movement and convey groundwater depending on their orientation relative to groundwater gradients. With the 2016 unstructured model, the 54 faults are inclined as they are in the geological model with a vertical resolution of approximately 10 to $20 \mathrm{~m}$, which is much finer than in the 2012 layered model. Each fault is split into six depth zones, each with independently adjustable parameters for PEST.

Based on our review of the SRK structural geology report (SRK 2011), four general fault groups were identified. During the calibration process, an attempt was made to match the fault characterisation interpreted by a structural specialist (SRK 2011) with the parametrisation of the 2016 unstructured model. PEST was used for the calibration of the in situ material properties related to the $3 \mathrm{D}$ geological model and the 54 faults individually by adjusting hydraulic conductivities. This was followed by manual adjustments to match-as closely as possible-fault characteristics as described in the SRK conceptual model (SRK 2011). Tikhonov regularisation was used with preferred parameter differences as prior information to best match the geological concept regarding relationships between the geological units. For example, the intrusive formation within the pit needed to be more permeable than the Hornfels unit, within specific permeability ranges. No prior information was used for the 54 faults. Faults are modelled within the mesh itself as elementals selections and discrete elements were not used since discrete elements in FEFLOW 7.1 can't behave as a barrier compared to the surrounding rock.

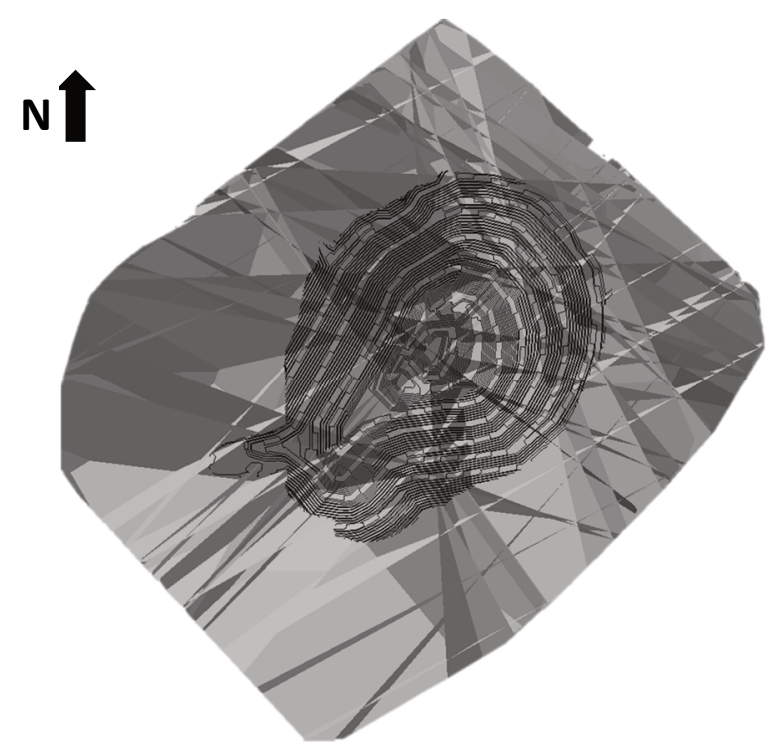

(a)

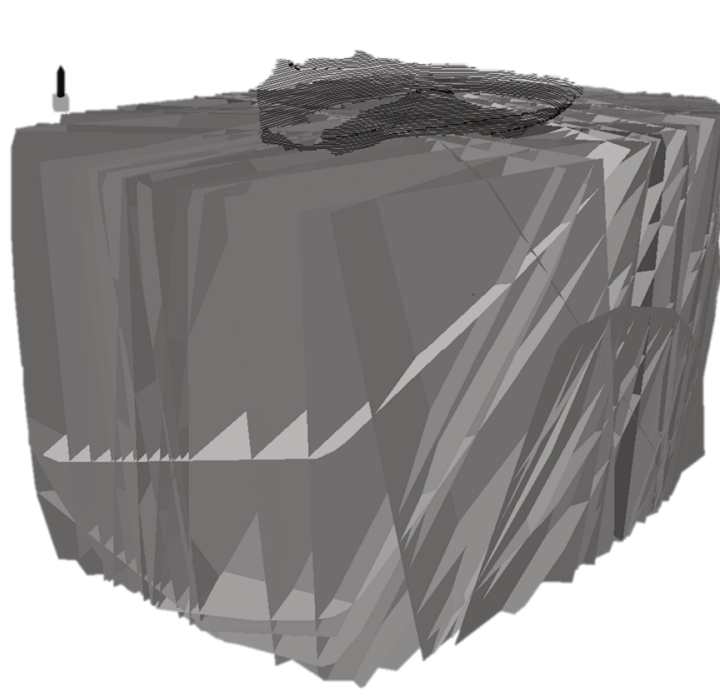

(b)

Figure 4 View of the $\mathbf{5 4}$ faults present in the open pit area then inserted as permeability zones the 2016 unstructured model. (a) Plan view of the 54 faults; (b) Angled view of the 54 faults 


\subsection{Comparison of the 2016 unstructured model of Antamina in FEFLOW 7.1 with the 2012 layered model in FEFLOW 6.0}

The FEFLOW mesh was constructed using the new TetGen capabilities of FEFLOW 7.1 (DHI 2015). DHI incorporated all the predictive pit stages explicitly into a single FEFLOW mesh. A balance must be found between the level of mesh detail and model computation time. Therefore, refinement associated with simulating future pit shells was prioritised over matching the mesh to historical pit shells, which will not significantly affect predictive simulations. Hence, the geometry of all the pit stages from the 2016 to 2036 mine plans are represented with high detail within the FEFLOW mesh by adjusting the mesh node locations to match the mine planes.

All the historical pit stages from 2000 to 2016 are represented using the nearest neighbour interpolation method to the closest FEFLOW node in the highly 3D refined pit zone area, Z1, in Figure 5 . The location of the sections NW to SE is presented lower in the text in Figure 6. All the pit boundary conditions and seepage nodes were set up with transient modulation functions to be activated at the right time. As a result, the 2016 unstructured model can be run from the pre-mining conditions, year 2000, transient calibration period to year 2016, through to the end predictive scenarios, year 2036, without any interruption of the computer during the simulation period. The use of a single mesh also allowed initial head conditions from the premining steady state calibration to be directly imported into the transient model. The single transient simulation includes the transient calibration period from 2000 to 2016 and the prediction period from 2016 to 2036. Since the zone $\mathrm{Z1}$ is highly refined, it's considered acceptable to import potential new mine planes in the mesh using nearest neighbour interpolation and not readjusting the mesh nodes to the mine planes. With the same logic, it's assumed that not having the mesh match the mine plans won't influence the transient calibration period from years 2000 to 2016.

The re-meshing of the 2016 unstructured model led to a reduction of the finite element mesh count by more than $70 \%$ ( 462,885 nodes in the 2016 model, compared to 1,620,360 nodes in the 2012 layered model (MWH 2012)), leading to a reduction in computational time by a factor of 5 . The final steady state runtime for the 2016 unstructured model was only 4 minutes, which is well-suited to undertaking run-intensive uncertainty analysis, if required. At the same time, the 2016 unstructured model features approximately twice the level of refinement in key areas of the open pit. The 2016 unstructured model domain (Figure 6) was extended to approximately five times the size of the 2012 layered model, allowing coverage of peripheral regions including the mine tailings storage facilities.

With FEFLOW 6.0, it was very challenging for the 2012 layered model to achieve a high mesh resolution in 3D in the area of interest without simultaneously increasing the resolution in other parts of the model because the model had to be constructed as a series of layers. Figure 5 illustrates how the 2012 layered model has an unattractively high level of refinement in areas far from the open pit or out of the zone of interest. Figure 5 also compares the finite element mesh of the 2012 layered model (bottom) with the 2016 unstructured model (top). In the 2016 unstructured model, a high level of mesh refinement was only defined for the pit zone (Z1) with a target element dimension of 10-20 m, and each node was adjusted to match each predictive mine plan perfectly. The area immediately surrounding the pit (Z2) presents coarser elements but enough detail to capture the hydrogeological gradients. In areas outside of the open pit (Z3), the level of refinement was reduced to increase the efficiency of the model simulation run time. 


\section{6 unstructured model}
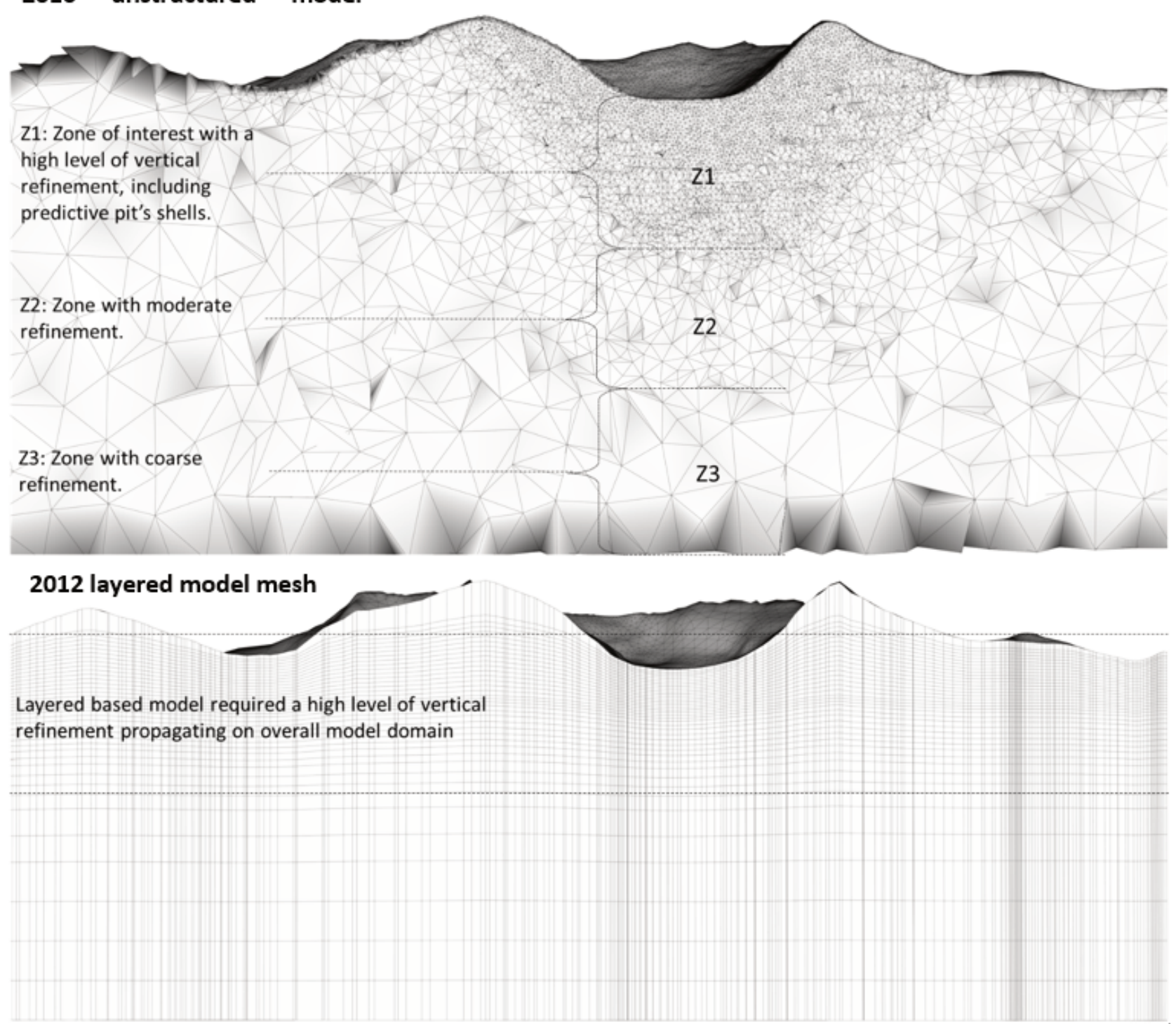

Figure 5 Northwest-southeast 2D section across the open pit of the 2012 layered model mesh (bottom) and the 2016 unstructured model mesh (top). Unstructured mesh allowed greater refinement around the pit area and less refinement regionally to achieve computational efficiency 


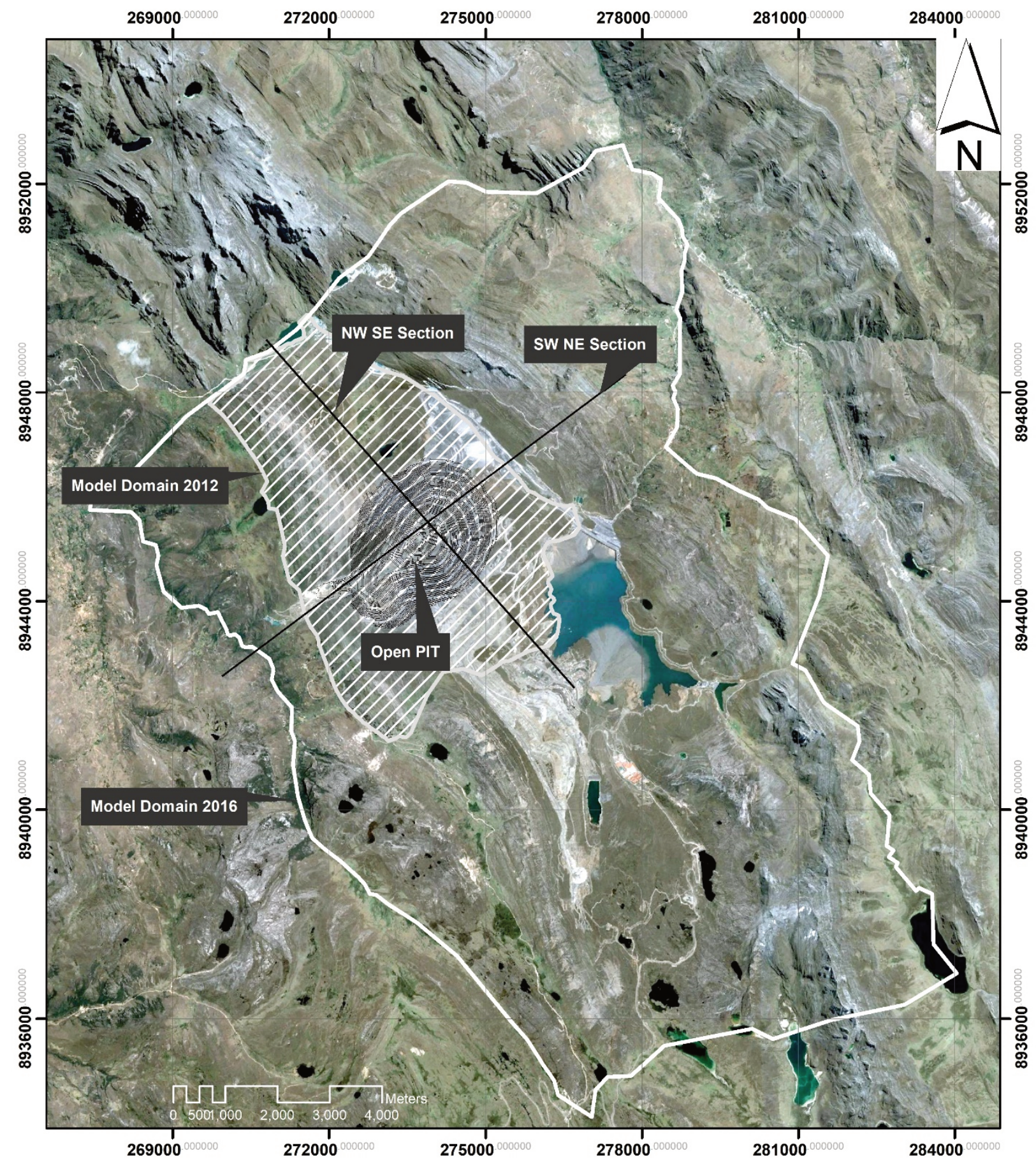

Figure 6 Antamina location map and limit of the 2012 model (lined polygon) versus the 2016 model

\section{6 unstructured model calibration}

Important objectives of the pre-mining steady state calibration were to achieve a reasonable match between observed and simulated heads (Figure 7) and to mimic the observed groundwater discharge to lakes, wetlands, springs and streams. Additional effort was applied to reproducing seasonal fluctuation due to recharge from precipitation during the wet season, especially notorious in the upper piezometers of most of the observation well clusters. Fluctuations of up to $50 \mathrm{~m}$ between wet season and dry season heads have been recorded. Equally important, since the pre-mining head calibration data are sparse, was a thorough review of the predicted watertable and hydraulic gradients in relation to the conceptual understanding of the groundwater system. During transient calibration over the 2000-2015 period, the hydraulic conductivity 
values and anisotropy estimated in the pre-mining steady state model were confirmed and the specific storage (Ss) was adjusted to better simulate the temporal trends in the heads observed in the piezometer network within the pit and surrounding areas. These parameters were also adjusted to better simulate the measured flows from the dewatering wells during pit development that are shown in Figure $7(\mathrm{~b})$ where the dark black dots are the measured flow rates and the grey dots are the modelled flow rates, including wet and dry seasons. During the transient calibration, it was important to confirm that areas that have not recorded head changes due to pit development (or are believed to have not been affected) are represented by the model as areas with no head change. Because changes in hydraulic parameters introduced during transient calibration would also influence the pre-mining period, the steady state calibration was revisited after each stage of the transient calibration. This back and forth methodology continued until both the steady state and the 2000-2015 transient models could simulate key flow processes in a consistent manner.

A total of 165 piezometers within the 2016 unstructured model domain passed the screening process for use in the pre-mining calibration including those which were backward interpolated to estimate pre-mining heads. For the transient calibration dataset, three 'snapshot' calibration dates were used. Continuous head measurements were not used to compute transient normalised root mean squared (NRMS) values on this project. The annual average piezometric levels measured onsite and simulated in the 2016 unstructured model were compared for years 2007, 2012 and 2015. The total number of piezometers considered reliable for these three snapshot years was 36,85 , and 57, respectively. The NRMS error was calculated for each of these years in the same manner as for the pre-mine steady state calibration. For this paper, only the pre-mining calibration plot is presented in Figure $7(\mathrm{a})$, with a value of $8 \%$ for the normalised root mean square (NRMS) error or a root mean square (RMS) error of $48 \mathrm{~m}$.

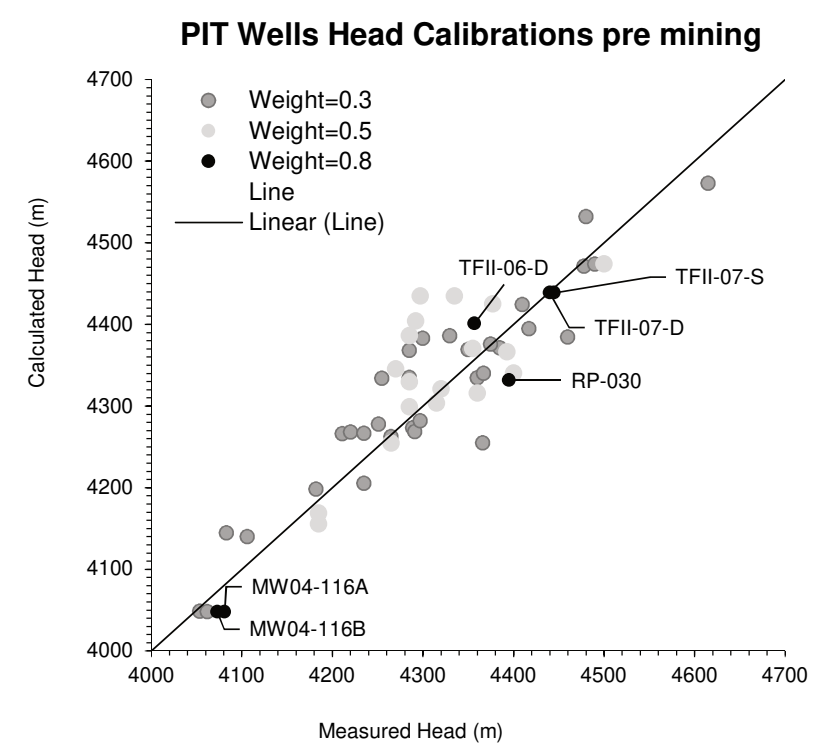

(a)
Flow rate calibration 2000 - 2015

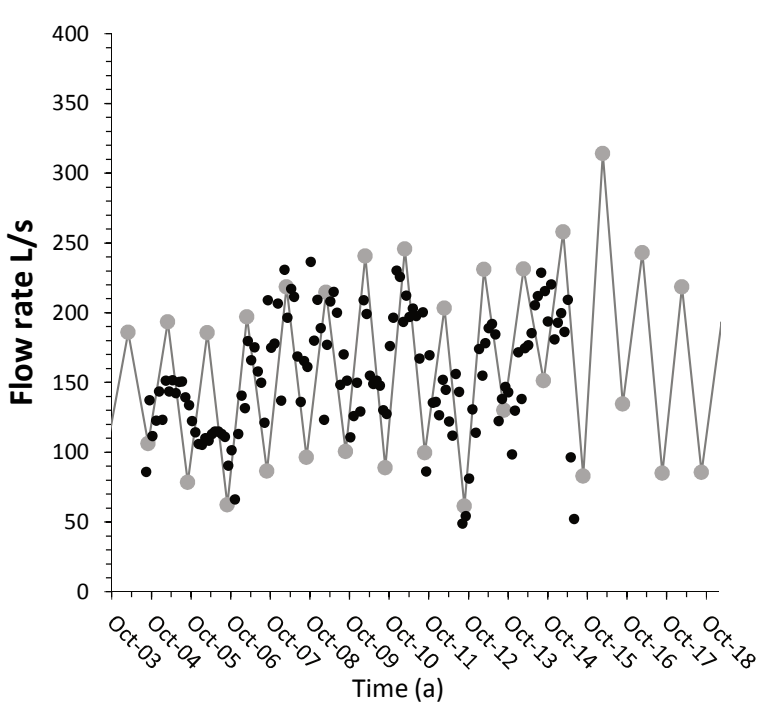

(b)

Figure 7 Calibration chart of the 2016 model. (a) Calculated head versus measured head for pre-mining conditions; (b) Calculated dewatering flow and modelled dewatering flow for 15 years of mining

\section{Optimisation of the dewatering scheme}

Once calibrated, the 2016 unstructured model was used as a tool to optimise Antamina's dewatering scheme. The objective of the optimisation is to use an innovative approach to propose a set of pumping rates and locations to dewater the Antamina pit to $50 \mathrm{~m}$ below the main pit base while minimising capital and operational dewatering costs. The scope of work comprised code writing and data pre-processing for wellfield optimisation. The hydraulic parameters from the calibrated 2016 unstructured model described in previous sections were used in the optimisation. 


\subsection{Objectives and methodology}

The objective used to define acceptable dewatering ahead of pit expansion was based on lowering the water level to $50 \mathrm{~m}$ below the pit bottom at the end of every year from 2016 to 2036, with the least number of pumping wells. The optimisation must respect the followings constraints:

- The program should identify the minimum number of pumping wells to achieve the desired objective.

- Pumping well locations are constrained spatially to be within an area defined as being safe for a well installation.

- Pumping wells for a given time cannot be placed in areas of the pit where rock is to be cut by mining operations during that time.

- The dimensions of the pumping wells are $30 \mathrm{~cm}$ in diameter and up to $250 \mathrm{~m}$ in depth (conceptual values that are believed to be reasonable based on the historical pumping rates in the Antamina pit).

- The maximum pump rate per well is considered $25 \mathrm{~L} / \mathrm{s}$, a conceptual value that is believed to be reasonable based on the historical pumping of the Antamina pit.

The method was based on multiple runs of a steady state model to minimise run time, and the optimisation was performed using the Monte Carlo approach. The optimisation was based on the following assumptions:

- The superposition principle applies for drawdown from different wells.

- A linear relationship between pumping rate and drawdown within the model is a reasonable approximation.

It's important to note that since the linear relationship is not strictly valid, a final check was performed (cf. point 4 below), running the model with the final well solutions to ensure that the objective function criteria were respected in the end. The optimisation is sub-optimal due to this simplification but running the full unconfined flow model for all well configurations and pumping rates would lead to longer computing times.

The work was divided into four principal steps listed below:

1. Pre-processing, which involves the division of the future 20 years of mine development into nine time periods, the definition of the accessible area for wells installation, and the selection of the observation point and candidate well locations.

2. Runs of steady state models for each time and each candidate well.

3. Optimisation using results of the steady state single-well runs to find the best combination of well locations and pumping rates.

4. Validation of the solution derived from steady state superposition with the transient model using the optimal well locations and pumping rates.

\subsubsection{Data pre-processing}

\subsubsection{Timeframe division into periods}

The optimisation covers 20 years from 2016 to 2036. As mentioned, the process is based on a series of steady state models. Since the configuration of the pit will change significantly over this period, the total simulation time was divided into nine periods shown in Table 1. 
Table 1 List of all the pit stages represented within the FEFLOW model and optimised during the optimisation process

\begin{tabular}{llllllll}
\hline Period & Start & End & Years & $\begin{array}{l}\text { Pit bottom } \\
\text { (masl) }\end{array}$ & $\begin{array}{l}\text { Water level } \\
\text { objective (masl) }\end{array}$ & Period & Start \\
\hline 1 & Dec 2017 & Dec 2021 & 4 & 3,796 & 3,746 & 1 & Dec 2017 \\
2 & Dec 2021 & Dec 2023 & 2 & 3,766 & 3,716 & 2 & Dec 2021 \\
3 & Dec 2023 & Dec 2025 & 2 & 3,736 & 3,686 & 3 & Dec 2023 \\
4 & Dec 2025 & Dec 2026 & 1 & 3,691 & 3,641 & 4 & Dec 2025 \\
5 & Dec 2026 & Dec 2028 & 2 & 3,646 & 3,596 & 5 & Dec 2026 \\
6 & Dec 2028 & Dec 2032 & 4 & 3,616 & 3,566 & 6 & Dec 2028 \\
7 & Dec 2032 & Dec 2034 & 2 & 3,601 & 3,551 & 7 & Dec 2032 \\
8 & Dec 2034 & Dec 3035 & 1 & 3,586 & 3,536 & 8 & Dec 2034 \\
9 & Dec 3035 & Dec 3036 & 1 & 3,541 & 3,491 & 9 & Dec 3035 \\
\hline
\end{tabular}

Two criteria were used to define these periods. The first was that the undisturbed area for potential wells in the pit bottom (see the definition of drilling area below) should not vary significantly over the period. The second criterion was that the advancement in pit depth should be constrained to a manageable amount in each period.

\subsubsection{Definition of pit bottom area and drilling area}

All of the candidate pumping wells were located in the pit bottom. The pit bottom area was defined as the pit shell surface that is $100 \mathrm{~m}$ above the lowest pit elevation (the distance of $100 \mathrm{~m}$ is arbitrary but leads to representative pit bottom area). The pumping wells must be located where no excavations will occur during the period. Thus, the available drilling area for each period is the intersection between the pit bottom area and the area with no excavations planned for the period. This means the code included a spatial solution to exclude areas for the optimisation and account for drilling limitations.

\subsubsection{Selection of the observations points}

Observation points were included in the FEFLOW model to confirm the degree of dewatering and assess how close the head is to the water level objective. For each period, observation points were located inside the pit bottom area and $100 \mathrm{~m}$ below the pit bottom (which is $50 \mathrm{~m}$ below the dewatering target and approximates the watertable in the pit area). Between 10 and 15 nodes were selected as observation points.

\subsubsection{Candidate wells selection}

For each period, the pumping wells were allowed to be any FEFLOW node located within $250 \mathrm{~m}$ below the pit shell inside the available drilling area. The result was a group of 1,000 to 1,500 nodes that could be candidates for pumping wells. A steady state FEFLOW simulation was run for each of the candidate nodes. To decrease the computational time, only one node was selected for any given $60 \times 60$ m square of pit bottom surface. Every candidate node was the one as close as possible to the square's centroid. This process reduced the candidate well locations to about 100 nodes per period, as presented in Figure 8, where the blue dots are the FEFLOW nodes and the red squares the candidate's selection. 


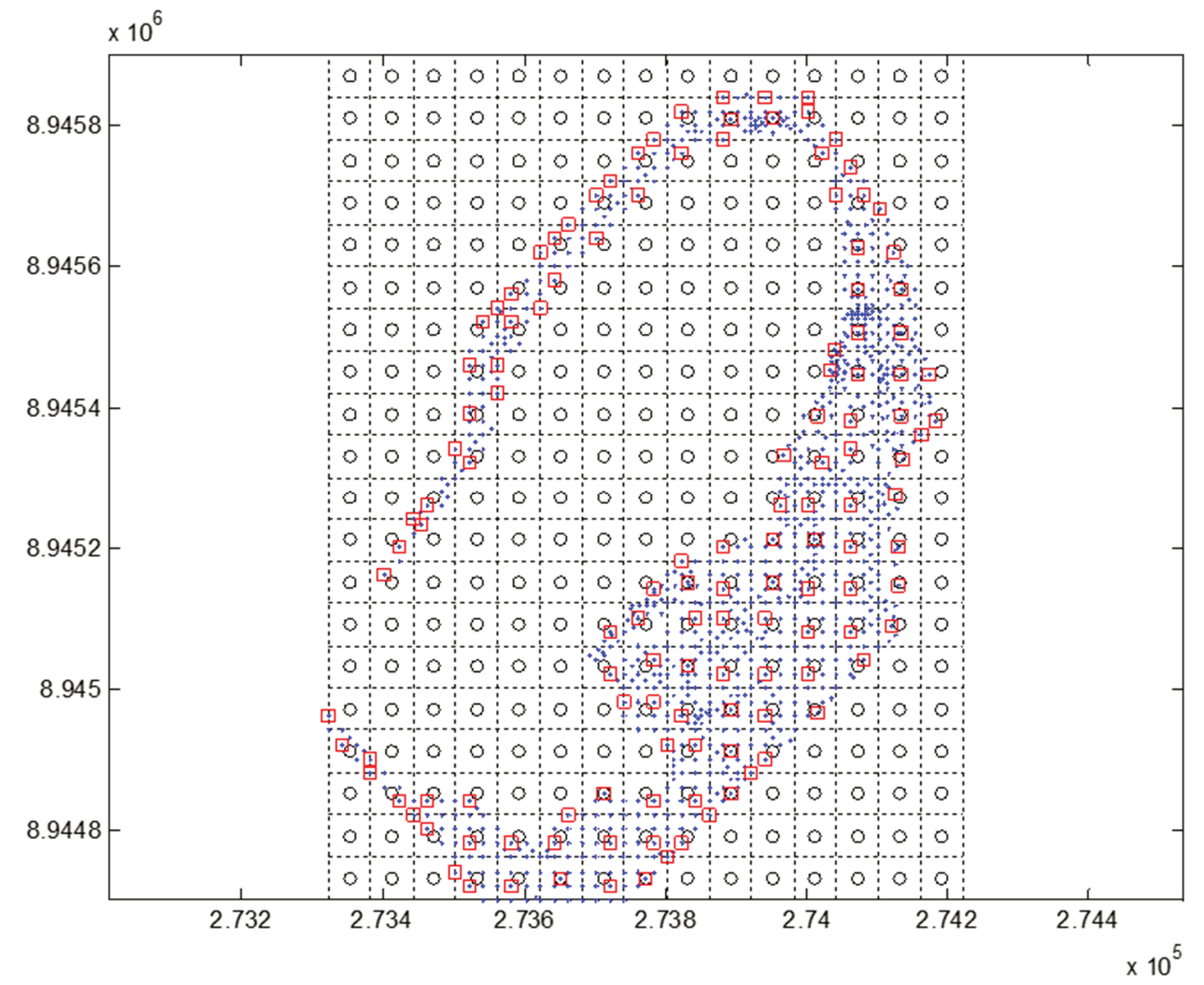

Figure 8 To decrease the computational time, only one node was selected for any given $60 \times 60 \mathrm{~m}$ square of pit bottom surface. Blue dotes are the FEFLOW mesh nodes for a specific pit stage, red squares are the well location candidates as close as possible to every square centroid

\subsubsection{Steady state runs}

For each period, a 3D FEFLOW steady state model was constructed. The pit design in the model corresponds to the last year of the time period. The boundary conditions in the pit were:

- Seepage nodes applied at the pit walls.

- A single pumping well in the pit bottom that corresponds to a single candidate well. For each time period, the model was run for each candidate well.

There are about 100 candidate wells for each period and 10 periods. Consequently, 1,000 steady state, single-well runs were completed. For each run, the hydraulic head results at the observation points were exported to be analysed during the optimisation process. The creation, execution and post-processing of the 1,000 steady state runs were automated via plug-ins within FEFLOW.

\subsubsection{Optimisation function}

The optimisation step determines the best combination of wells to achieve the target dewatering level with the lowest economical cost possible. The optimisation consisted of testing various combinations of wells. The well combinations were obtained using the Monte Carlo method that explores the space of possible solutions. Then, for each well combination, the water level at the observation points was calculated from the steady state model. To determine the best scenario, an objective function was developed to reach the target drawdown at the observation wells for the lowest cost. The entire process of the optimisation was coded in MATLAB. The code used as input the head simulated at the observation points in the steady state models with single pumping wells. 


\subsubsection{Monte Carlo approach}

To explore the variability of possible activated wells and pumping rate combinations, the Monte Carlo method was used. In a Monte Carlo analysis, random combinations of active wells and pumping rates are tested and analysed. For this project, the complete head solution for a given Monte Carlo iteration was not assessed. Rather, the predicted drawdown at the selected observation points were assessed for each Monte Carlo assessment. The problem was further simplified by applying the linearity assumption to the groundwater flow solution. When linearity applies, drawdown at each observation point can be estimated with reasonable accuracy using the superposition principle (Bear 1979). The principle of superposition allows one to sum the solutions of linear equations. Therefore, knowing the drawdown due to one pumping well, one can compute the drawdown due to multiple pumping wells by summing the drawdowns from each well. Once the drawdown and thus, the head at the observation points for each well combination is calculated, the best combination can be determined.

\subsubsection{The objective function}

A cost-objective function was incorporated into the optimisation problem to assess the cost and efficiency of each proposed solution. This implicitly considers the cost related to the installation of all wells and pumping rates, in this case solely based on the number of wells used. To ensure that the selected well configuration meets the efficiency measure, two penalty functions were applied: a penalty term due to insufficient drainage, and a second penalty term when the watertable drops below the well screen level.

$$
f=n a+\sum_{i=1}^{n}\left(q_{i} p\right)+\sum_{j=1}^{m} \Delta H_{j}^{2} a
$$

where:
$a=$ well activation cost.
$n=$ number of wells.
$q_{i} \quad=\quad$ pumping rate $f$ or the $i_{t h}$ well.
$p \quad=$ cost per pumping rate unit.
$\Delta H_{j}^{2}=$ square of head exceeding constraint for $f$ or the jth observation point.

Figure 9(a) shows an example of the typical output graph of the optimisation process. The vertical axis represents the number of wells. The horizontal axis shows the electricity costs for the pumping, which corresponds to the second term of the objective function. The colour bar is the total value of the objective function. Solutions with too few wells have lower electricity costs (e.g. two, three, and four wells) fail to achieve the desired dewatering goal or include wells that go dry at the fixed pumping rate of $25 \mathrm{~L} / \mathrm{s}$. These solutions (indicated by red circles) are penalised by the third term of the objective function. In this example, the solutions that respect the optimisation constraints require at least five wells. Therefore, the optimisation consists of finding the combinations of five wells with the minimum electricity cost. The electricity cost is lower in wells closer to the lowest level of the pit bottom. It is important to note that the cost of pumping water from the pit floor to the pit crest is not included in the objective function of the current methodology. Future versions will consider this factor, as it underestimates the costs associated with in-pit well pumping. Conceptually, ex-pit wells are generally preferred over in-pit wells, and the logic to support this preference will be incorporated in future analyses. Figure 9(b) shows an example of the mesh nodes used for an optimisation period. The small red circles are the pit geometry, the blue circles the observation nodes, the green circles the candidate wells (nodes) and the large red circles the optimised wells. 


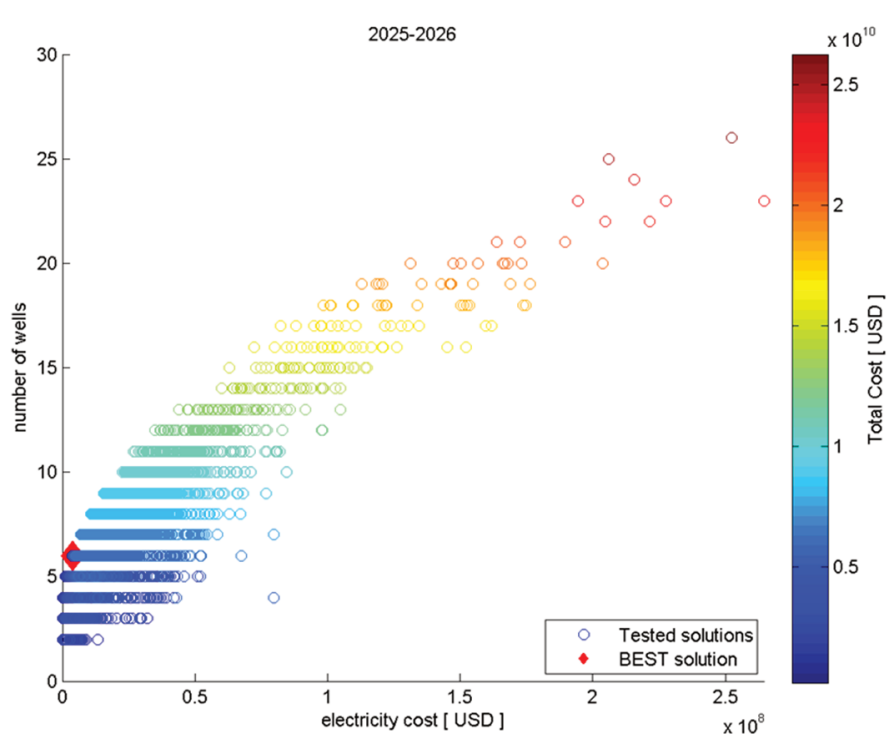

(a)

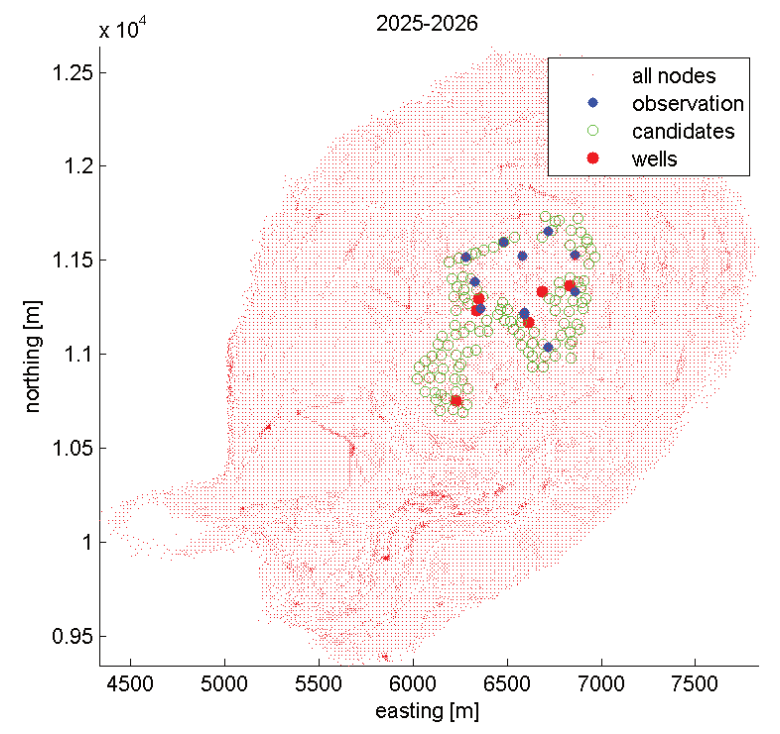

(b)

Figure 9 (a) Example of the typical output graph of the optimisation process. The vertical axis represents the number of wells and the horizontal axis is the electricity cost in USD; (b) Plan view of the dewatering solutions

\subsubsection{Validation of the steady state solution with transient}

For each time period, the optimisation process gives the number, location and rate of the required pumping wells. The optimisation result, which is based on a simplifying assumption of linearity and on steady state model predictions of drawdown, was validated in FEFLOW with the 2016-2036 transient model. The pumping wells were implemented as hydraulic head boundary conditions with minimum and maximum constraints in the same manner as used in the steady state single-well models created for the Monte Carlo analysis. Adjustments to the well locations and pumping rates were required when the optimisation results were scaled up to a fully transient, unconfined and partially saturated simulation. Most of the adjustments consisted of regrouping some wells placed at a close distance proposed by the optimised solution in extending the lifetime of one single, deeper well at one location. In a few other cases, increased flow rates were necessary to match the dewatering objective function target, due to the linearity and steady state approximations.

\subsection{Optimisation results}

A total of 45 pumping wells are needed for dewatering from 2017 to 2036. Some pumping wells are active for more than one time period. The resulting pumping plan is presented in Figure 10 . The total pumping rate ranges from $115 \mathrm{~L} / \mathrm{s}$ in 2017 to $151 \mathrm{~L} / \mathrm{s}$ in 2036. The total water pumped through to 2036 in the optimised case is $190 \times 10^{6} \mathrm{~m}^{3}$ (million cubic meters). As the pit deepens, the hydraulic conductivity of the intrusive decreases. Consequently, the pumping rate per well must be lowered due to reduced well capacity. Thus, after 2028, the number of pumping wells must be increased to make up for the reduction in pumping capacity. As a comparison with the original non-optimised Antamina dewatering plan, the optimised number of wells for that year are seven versus the 10 planned, representing a cost-saving equal to three wells. Through to 2028, the optimised case requires 27 dewatering wells versus the 34 new wells required in the current Antamina plan, representing a cost-saving equal to seven wells. The results indicate that the constraints on well placement impose an important limitation in the analysis and that the number of wells required is also highly dependent on the hydraulic conductivity of the main intrusive. The hydraulic conductivity of the intrusive at depth remains poorly defined at this time and therefore the uncertainty in these important variables is high. The optimisation routine can be rerun once additional hydraulic properties data are available. 

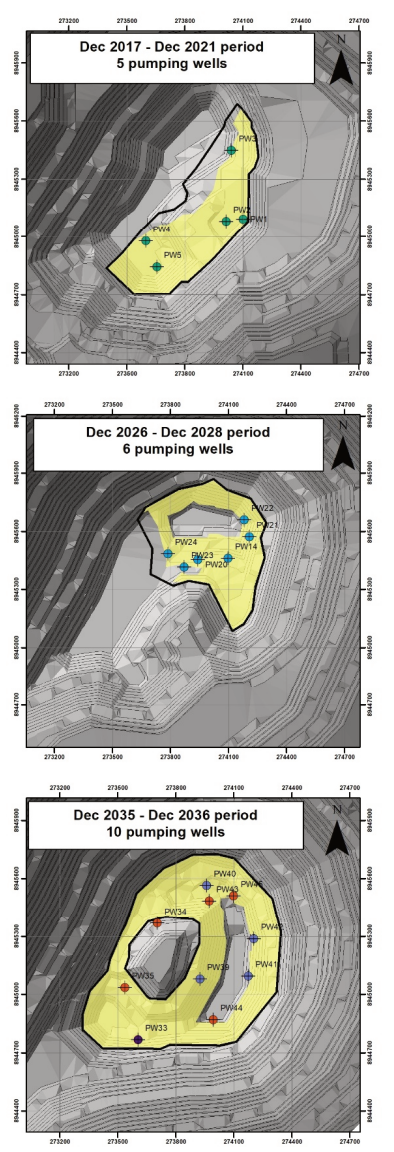
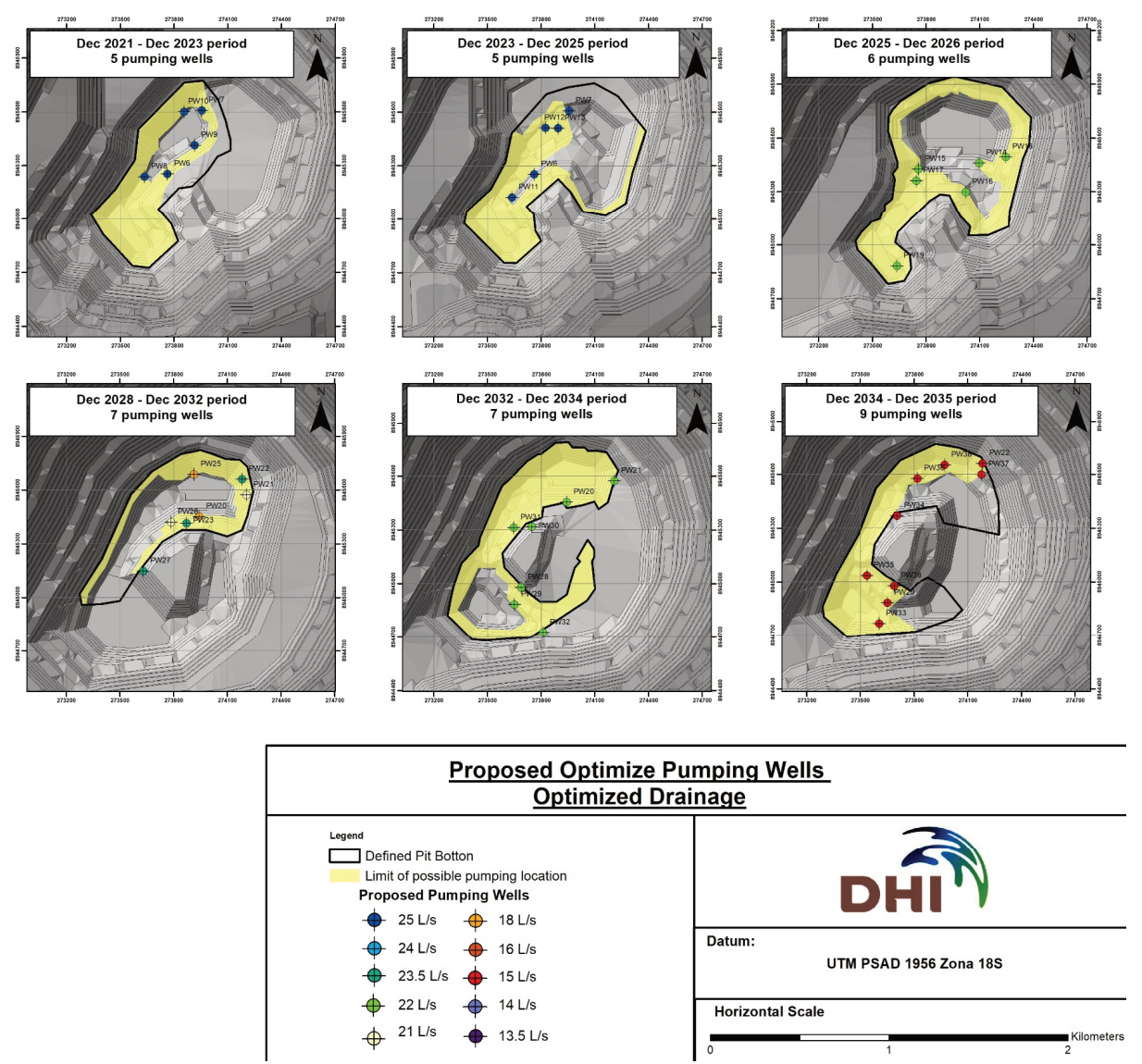

Figure 10 A total of 45 pumping wells are needed during dewatering from 2017 to 2036 . Some pumping wells are active for more than one period. Through to 2028, the optimised case requires 27 dewatering wells versus the 34 new wells required in the current Antamina plan, representing a cost saving equal to seven wells

\section{Pore pressure estimates from data fusion of model and measurement data}

\subsection{Objective}

Besides finding the optimal dewatering strategy, another key purpose of the 2016 unstructured model was to provide pore pressure estimates in the pit slopes. Pore pressure values are a fundamental input to geomechanical models for the determination of pit slope stability safety factors. Direct measurements and numerical models are the main tools for obtaining this input, each having different strengths and drawbacks. Direct observations are usually very accurate and allow real-time monitoring but are sparsely distributed in space. The 2016 unstructured model provides spatially continuous pore pressures and allows forecasting but suffers from model-to-measurement misfits. There are multiple reasons for these misfits, the most important being:

- The model is a simplification of reality and due to the complex hydrogeology in Antamina, the numerical model cannot reproduce all of the details of the real-world system.

- The hydraulic parameters of large portions of the model area, especially at depth, cannot be directly measured and have been shown to be of low identifiability.

- Inaccuracies in model boundary conditions, such as unforeseen rainfall events increasing water levels within short periods of time and discrepancies between the modelled and actual dewatering operations. 
Optimal knowledge of hydraulic heads can hence be obtained by combining model results with direct measurements to take advantage of their relative strengths. This was already performed to some degree during calibration. However, several authors (Moore \& Doherty, 2006; Cawley \& Talbot, 2010; Lever 2016) have shown that calibration can only improve a model's predictive capabilities up to a point, beyond which further improvement in calibration (expressed by a reduction of the RMS) can result in a lower predictive accuracy due to a situation known as overfitting (Moore \& Doherty, 2006; Hawkins, 2004; Srivastava et al., 2014).

Consequently, the model's output could still contain a bias even after an optimal calibration has been achieved and such bias could propagate into the pit slope stability model if uncorrected. This uncertainty can be managed by applying safety margins to the watertable. In the case of the Antamina study, this was done by developing a worst-case scenario model (low drainage scenario). For the low drainage scenario, the following modifications for the key parameters were conducted:

- Decrease hydraulic conductivities (K) globally (including the three principal axes) by a factor of 2 .

- Increase recharge globally $10 \%$, or divide recharge rates by 1.10 .

- Increase Ss by a factor of 2 .

Since more accurate measurements of pore pressures are available at some locations, an alternative approach would be to use this information to further reduce the discrepancies between the modelled and absolute pore pressures before passing the model outputs to subsequent assessments. Data fusion is one such method that substantially reduces model biases by merging the output from the calibrated model with the actual observation data before passing it on to the pit slope stability assessment, hence allowing for less conservative safety margins.

\subsection{Methodology}

Bias correction, in its simplest form, calculates a correction function based on the difference between model results and measured values (bias). This usually involves some form of interpolation of the bias between sampled observation points.

The data fusion method extends this approach by incorporating geostatistical concepts. Based on past performance of the model, the likely spatial and temporal distribution of the model error is estimated at unsampled or forecasted locations, including its spatial and temporal variability. By correcting for this bias, it is possible to estimate the most likely system state based on Bayesian principles, including uncertainty margins. This is also known as the 'best linear unbiased estimate'.

Consequently, the data fusion approach creates a hybrid model. Close to sampled locations, the result mostly relies on direct measurements, and the uncertainty of these values is as low as the measurement error of the corresponding device. With increasing distance (in space and/or time) from an observation point, the result relies on the head gradients calculated by the model to interpolate between the known locations. The resulting continuous head distribution, therefore, relies on direct measurements to gain high accuracy of watertable absolutes and on the model to incorporate gradient changes, e.g. from geological structures, dewatering, or natural boundary conditions. This process is illustrated in Figure 11.

It is important to note that the data fusion method is only applicable to model outputs that are directly measurable (e.g. it cannot improve the prediction of water inflows based on water levels alone). It also does not induce any changes to the model parameters (setting it apart from data assimilation methods). The advantage of the data fusion process is that it does not require re-running the model, therefore the correction can be performed in real-time, making it an ideal tool for online monitoring systems. 


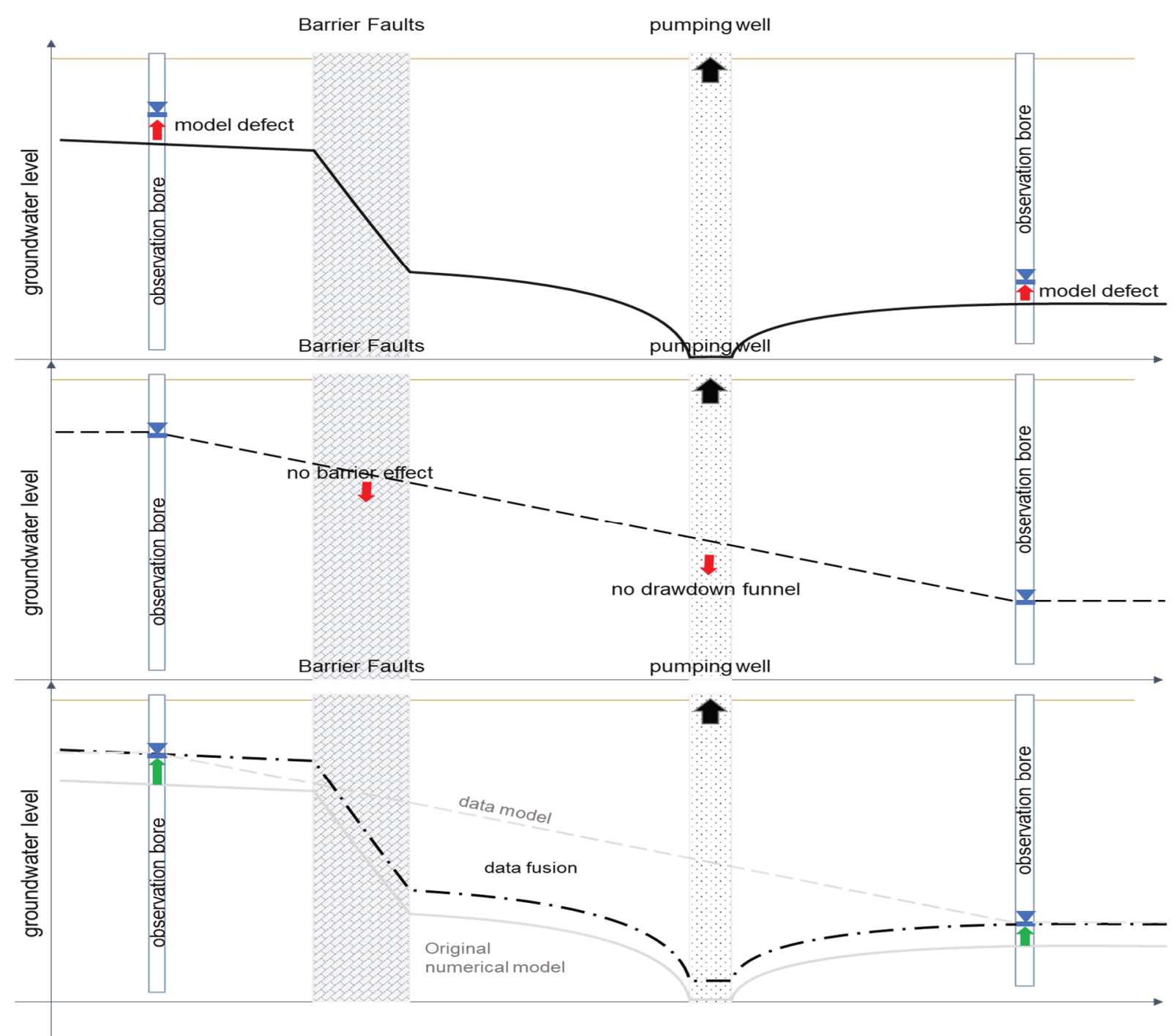

Figure 11 The data fusion approach creates a hybrid model that uses the continuous spatial predictions of a physical model and the direct measurement data, which minimises the model uncertainty ('best linear unbiased estimate')

\subsection{Results}

The method was applied to the Antamina model using measurement data from early 2015 (approximately 15 years after the commencement of dewatering operations) as a case study. Data from 34 pressure transducers was available during this period. Comparison between the predicted and measured water levels showed a deviation of around 5\% NRMS error in the pit area, and 12\% NRMS error using all the water level information.

Data fusion was applied to obtain a continuous hydraulic head distribution for pore pressure analysis that combined the benefits of modelling and actual measurements.

As expected, the head representation for the year 2015 is substantially more accurate after the bias correction. Figure 12 shows a significantly better fit, with the NRMS error reduced to $1.7 \%$ (from $5 \%$ ) for the pit area and $2.2 \%$ (from $12 \%$ ) in the overall area. Note that it would be possible to reduce the RMS error to true zero, however, experience has shown that allowing some residual deviation is helpful to obtain a more stable interpolation by the underlying kriging estimator.

The same exercise was repeated for the 2000 pre-mining condition where the NRMS error dropped from $8.5 \%$ (all wells) and $4.8 \%$ (pit Area) to $1.7 \%$ (all wells) and $0.9 \%$ (pit area) respectively. 

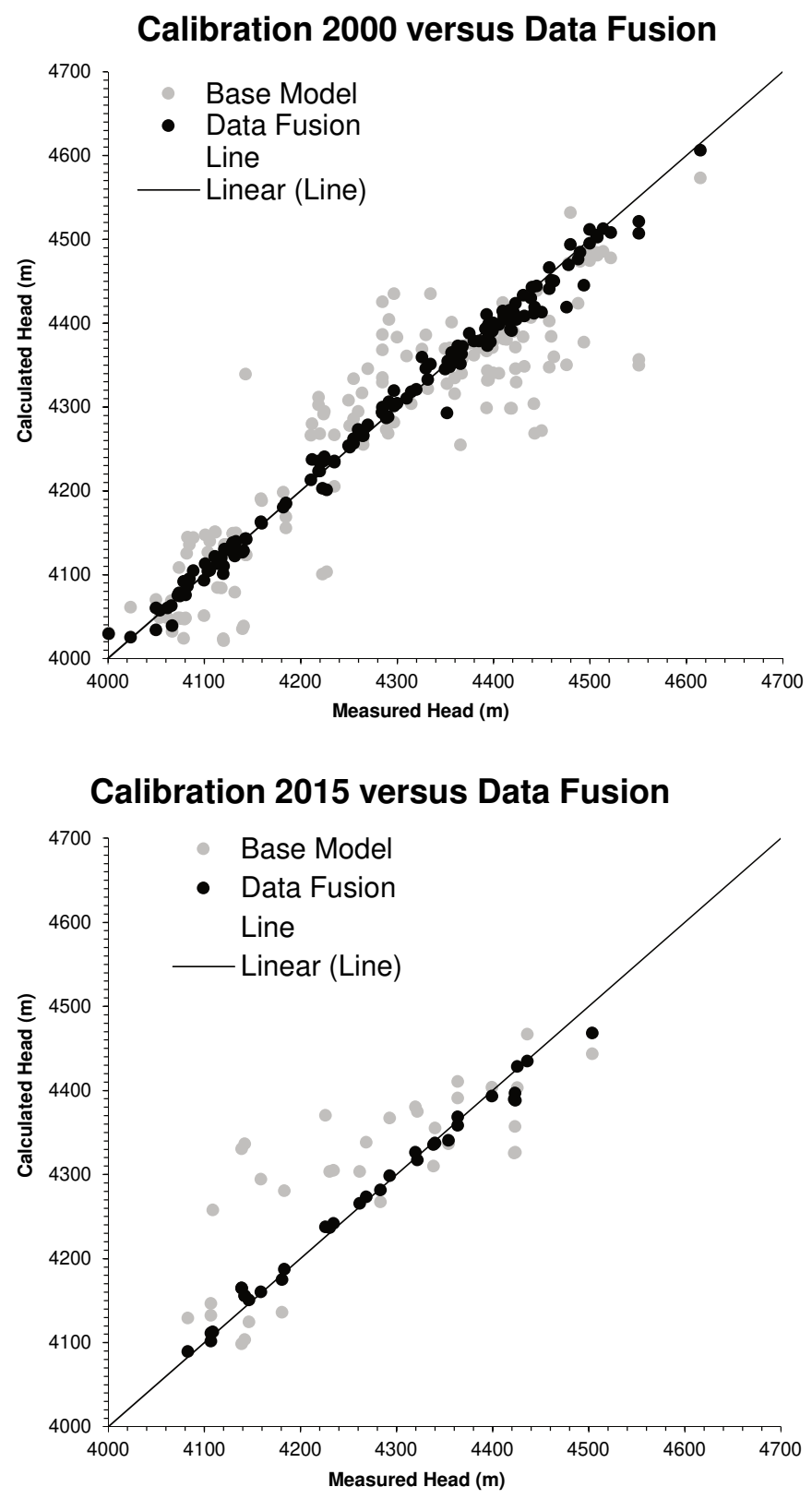

Figure 12 Calibration chart example considering the data fusion (black) solution using the year 2000 and 2015 calibration targets versus the calibrated 2016 unstructured model (grey)

Figure 13 compares the watertable of the data fusion results (black) with the watertable of the calibrated 2016 unstructured model (grey). Also shown is the worst-case scenario in terms of pressure (low drainage scenario, red) as well as the worst-case scenario in terms of flow rate (high drainage scenario, blue). These are projected onto two cross-sections through the pit walls for 2015, sections locations are shown in Figure 7.

The water level based on measured values (data fusion result) in this part of the pit is generally equal to or lower than the level originally predicted by the calibrated 2016 unstructured model (grey). This shows how the data fusion method has performed a bias correction in areas where actual measurements deviate from the model prediction. It also means that the calibrated 2016 unstructured model (grey) is slightly more conservative since it's overpredicting the pore pressure.

More importantly, the data fusion result allows a validation of the pit slope safety analysis. If the actual watertable would exceed the water level of the worst-case (low drainage) scenario, the safety could not be guaranteed as the geomechanical model would have been based on too low a pore pressure distribution. 
Instead, it can be seen that the actual water level fits well into the uncertainty margins based on the two extreme scenarios (high and low drainage), confirming the validity of the original pit slope safety calculations.

This testing exercise demonstrates how data fusion allows for continuous validation of the pit slope safety factors not only at the observation wells but for the complete pit area covered by the groundwater model.

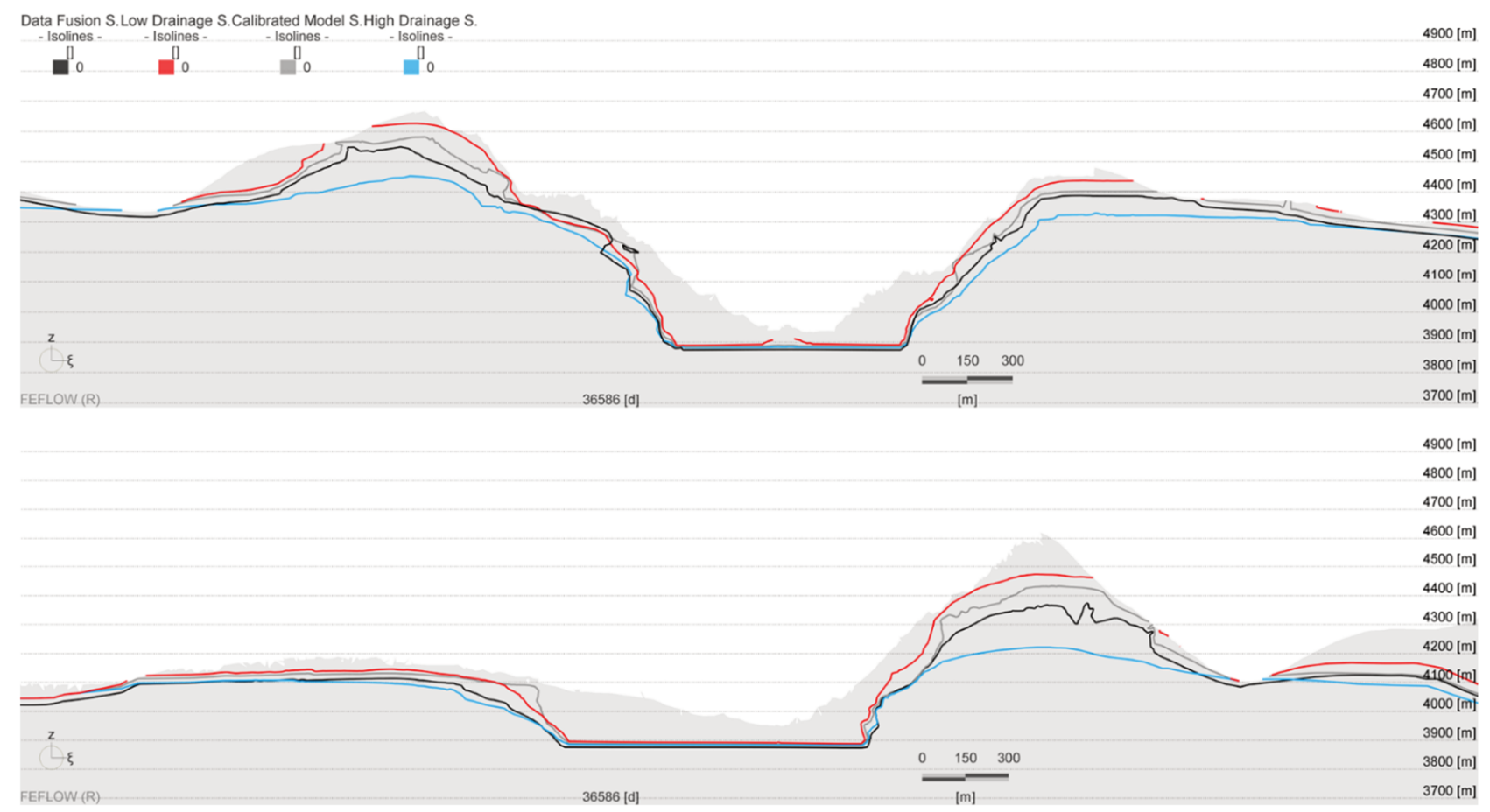

Figure 13 Sections northwest-southeast (up) and southwest-northeast (bottom) across the open pit showing the data fusion result of zero pressure line (black) compared to the calibrated model solution (grey) and sensitivity runs with high drainage scenario (blue) and low drainage scenario (red)

\section{Discussion}

The Antamina site has a very complex geology and, therefore, complex hydrogeology, as seen in multiple sources of hydrological and monitoring information. This paper presents new methodologies applied to improve confidence in the numerical flow modelling prediction of the Antamina open pit and surrounding areas, considering the hydrogeological complexity. The new FEFLOW 7 mesh flexibility was demonstrated to be an efficient solution to achieving suitable model run times and a higher level of refinement in the zone of interest. It could be considered as a replacement of typical 2D vertical sections for pore pressure modelling, incorporating a complete 3D detailed solution. Besides, the mesh flexibility of the new calibrated 2016 unstructured model allowed other uses such as a preliminary impact assessment tool for a new mine plan or new elements such as tunnels or changes in the tailing design. In terms of calibration and uncertainty, the Antamina site is very complex due to the hydrogeological heterogeneity. It is challenging to represent the complexity of the measured information.

Oversimplifying the model by ignoring the complexity and compartmentalisation effects due to faults and structures could lead to non-conservative scenarios and overestimating dewatering effects. On the other hand, including all the complexity would lead to longer run times and makes it impractical when trying to explore the uncertainty of model predictions. An uncertainty analysis has not yet been completed on this model; which is planned for completion in 2020. Since the 2016 unstructured model run time is fast-around 4 minutes in steady state conditions-it should be feasible without using a proxy model, but this needs to be defined. In terms of predictions, the optimisation process was shown to be feasible with reasonable runtimes using cloud computing. A potential cost reduction of approximately $10 \%$ was realised compared to the original dewatering plan. Even if partially included, operational and safety constraints need to be further investigated and implemented into the algorithm in order to have a more realistic optimised dewatering well 
plan. Also, it is important to note that the cost of pumping water from the pit floor to the pit crest is not included in the objective function of the current methodology. Future versions will consider this factor as it underestimates the costs associated with in-pit well pumping. Conceptually, ex-pit wells are generally preferred over in-pit wells, and logic to support this preference will be incorporated in future analyses. Again, it would be recommended to combine the optimisation process with a complete uncertainty analysis.

Finally, the data fusion method was tested to perform the bias correction of the predicted head distribution using sparsely distributed observations bores. The test has shown that the combination of actual measurement data and a physics-based model can create more accurate pore pressure predictions for the pit slope stability calculation. Because the data fusion result is based on actual measurement, it is substantially more accurate than the predictions based on modelling alone. At the same time, because it was applied to the 2016 unstructured model, the result covers the entire model area instead of just the bores. Due to its low computational demand, this method could be used in a real-time monitoring system of pit slope safety, if tied to a geotechnical slope stability model. The test case has also shown that the measured water levels are well within the expected range of uncertainty derived from the sensitivity analysis of the Antamina model and that the 2016 unstructured model slightly overestimates the pressure compared to the test case, which is considered conservative.

\section{Conclusion}

The unstructured mesh allowed for the inclusion of inclined faults within the pit area while maintaining a practical model processing time. The inclusion of these faults was essential for capturing local and sector-scale drainage responses. The unstructured mesh also allowed very detailed representation of the mine plans within the 2016 unstructured model mesh. For such a complex model with numerous data points for calibration, it is not possible to have an exact match of the head trends for all observation points. However, the model does match the general trends within the various pit sectors and the pressure trends throughout the open pit. The model also adequately reproduces the hydraulic gradients in the different pit sectors. Furthermore, the simulated historical mine outflow rates are well-calibrated to the measured outflows.

The 2016 unstructured model dewatering plan was successfully optimised to reduce OPEX and CAPEX. As a comparison with the original non-optimised Antamina dewatering plan, the number of wells has been reduced from the originally planned 10 to seven following the optimisation, representing a cost saving equal to three wells. Through to 2028, the optimised case requires 27 dewatering wells versus 34 new wells required in the current Antamina plan, representing a total cost-saving equal to seven wells.

The data fusion method has been demonstrated as a powerful option to improve real-time monitoring of the water levels and pore pressure by combining actual measurement with the model predictions. If incorporated into an operational system, it would allow a continuous validation of the pit slope safety. The test exercise of data fusion also demonstrated that for this particular case of Antamina, the water levels are within the uncertainty margins initially reported in the sensitivity analysis and that the 2016 unstructured model slightly overestimates the pressure compared to the test case, which is considered conservative.

A more extensive publication regarding Antamina's work is planned to be published in 2020-2021 with more details and information regarding the Antamina site, uncertainty analysis, and more in-depth use of the data fusion method.

\section{Acknowledgement}

The optimisation work was conducted by DHI Peru in collaboration with the University of Neuchâtel, Switzerland, and Professor Philippe Renard's team, part of The Centre for Hydrogeology and Geothermic of University of Neuchâtel (CHYN). We acknowledge the strong support from Philippe Renard's team. Also, to thank for the support of DHI Germany with the vital help of Dr. Carlos Andres Rivera and Professor Fabien Cornaton solving internal difficulties with the unstructured mesh. Finally, we acknowledge the assistance of Jens Schumacher for his help with the Amazon Cloud computing settings. We also thank Ryan Jakubowski for 
the support and inputs regarding the conceptual model of the Antamina site, concepts being the base for the numerical model, and Michael Gabora of DHI US and Michael McGlone for their mine dewatering input. Finally, we heartily thank Antamina Peru for allowing the publication of the work done and their meaningful participation in the project. The methods applied in this study are part of an ongoing PhD project by Robin Dufour and being able to use real data from Antamina makes it possible to share the learning of many years of work and effort.

\section{References}

Beal, G 2014, Guidelines for evaluating water in-pit slope stability, Appendix 4, CSIRO Publishing, Melbourne.

Bear, J 1979, Hydraulics of Groundwater, Dover Publications Inc, New York.

BISA 2015, Informe Técnico: Modelo Leapfrog Antamina, computer software, Lima.

Cawley, GC \& Talbot, NLC 2010, 'On Over-fitting in Model Selection and Subsequent Selection Bias in Performance Evaluation', Journal of Machine Learning Research, vol. 11, pp. 2079-2107.

DHI 2013, FEFLOW, version 6.2, computer software, DHI Institute for Water and Environment, Hørsholm, https://www.dhigroup.com/mikebydhi/products/feflow

DHI 2016, FEFLOW, version 7.0, computer software, DHI Institute for Water and Environment, Hørsholm, https://www.dhigroup.com/mikebydhi/products/feflow

Doherty, J 2016, Model-Independent Parameter Estimation User Manual, Watermark Numerical Computing.

Flosolutions 2015, Informe Técnico: Revisión de la información histórica y definición de modelo conceptual (Technical Report: Review of historical information and definition of conceptual model), Lima.

Geoslope 2012, SEEP/W, computer software, computer software, Canada, Calgary, http://downloads.geoslope.com/geostudioresources/8/0/6/books/seep\%20modeling.pdf?v=8.0.7.6129

Hawkins, DM 2004, 'The Problem of Overfitting', Journal of Chemical Information and Computer Sciences, vol. 44, issue 1, pp. 1-12.

Itasca 2012 FLAC3D, version 5.0, computer software, USA, Minneapolis, http://itasca-software.s3.amazonaws.com/ resources/flac3d_600_modeling.pdf

Lever, J 2016, 'Model selection and overfitting', Nature Methods, vol. 13, no.9, pp. 703-704.

MWH 2012, Informe Técnico: Antamina Pit Pore Pressure, internal report, Lima.

Moore, C \& Doherty, J 2006, 'The cost of uniqueness in groundwater model calibration', Advances in Water Resources, vol. 29, no.4, pp. 605-623.

Srivastava, N, Hinton, G, Krizhevsky, A, Sutskever, I \& Salakhutdinov, R 2014, 'Dropout: A Simple Way to Prevent Neural Networks from Overfitting', Journal of Machine Learning Research, vol. 15, pp. 1929-1958.

SRK 2011, Informe Técnico: Update to the Structural Model for the NE wall Antamina mine, internal report, Lima.

WMC 2009, Informe Técnico: Hydrogeological Update and Mine Dewatering Status Report, internal report, Lima. 